\title{
Management of patients with increased risk for familial pancreatic cancer: updated recommendations from the International Cancer of the Pancreas Screening (CAPS) Consortium
}

\author{
Michael Goggins [() , ${ }^{1}$ Kasper Alexander Overbeek 주, ${ }^{2}$ Randall Brand, ${ }^{3}$ \\ Sapna Syngal, ${ }^{4}$ Marco Del Chiaro, ${ }^{5}$ Detlef K Bartsch, ${ }^{6}$ Claudio Bassi, ${ }^{7}$ Alfredo Carrato, ${ }^{8}$ \\ James Farrell, ${ }^{9}$ Elliot K Fishman, ${ }^{10}$ Paul Fockens, ${ }^{11}$ Thomas M Gress (10, ${ }^{12}$ \\ Jeanin E van Hooft, ${ }^{13}$ R H Hruban, ${ }^{14}$ Fay Kastrinos, ${ }^{15,16}$ Allison Klein, ${ }^{17}$ \\ Anne Marie Lennon, ${ }^{18}$ Aimee Lucas, ${ }^{19}$ Walter Park $\left(10,{ }^{15}\right.$ Anil Rustgi, ${ }^{16}$ \\ Diane Simeone ${ }^{20}$ Elena Stoffel, ${ }_{1}^{21}$ Hans F A Vasen, ${ }^{22}$ Djuna L Cahen, ${ }^{2}$ \\ Marcia Irene Canto, ${ }^{18}$ Marco Bruno, ${ }^{2}$ International Cancer of the Pancreas Screening \\ (CAPS) consortium
}

Additional material is published online only. To view please visit the journal online (http://dx.doi.org/10.1136/ gutjnl-2019-319352)

For numbered affiliations see end of article.

Correspondence to Dr Michael Goggins, Pathology, Medicine Oncology, Johns Hopkins University, Baltimore, Maryland, USA; mgoggins@jhmi.edu

Received 23 June 2019 Revised 5 September 2019 Accepted 28 September 2019 Published Online First 31 October 2019

\section{Check for updates}

(C) Author(s) (or their employer(s)) 2020. No commercial re-use. See rights and permissions. Published by BMJ.

To cite: Goggins $M$ Overbeek KA, Brand $R$, et al. Gut 2020;69:7-17.

\section{ABSTRACT}

Background and aim The International Cancer of the Pancreas Screening Consortium met in 2018 to update its consensus recommendations for the management of individuals with increased risk of pancreatic cancer based on family history or germline mutation status (high-risk individuals).

Methods A modified Delphi approach was employed to reach consensus among a multidisciplinary group of experts who voted on consensus statements. Consensus was considered reached if $\geq 75 \%$ agreed or disagreed.

Results Consensus was reached on 55 statements. The main goals of surveillance (to identify high-grade dysplastic precursor lesions and T1NOMO pancreatic cancer) remained unchanged. Experts agreed that for those with familial risk, surveillance should start no earlier than age 50 or 10 years earlier than the youngest relative with pancreatic cancer, but were split on whether to start at age 50 or 55 . Germline ATM mutation carriers with one affected first-degree relative are now considered eligible for surveillance. Experts agreed that preferred surveillance tests are endoscopic ultrasound and MRI/magnetic retrograde cholangiopancreatography, but no consensus was reached on how to alternate these modalities. Annual surveillance is recommended in the absence of concerning lesions. Main areas of disagreement included if and how surveillance should be performed for hereditary pancreatitis, and the management of indeterminate lesions.

Conclusions Pancreatic surveillance is recommended for selected high-risk individuals to detect early pancreatic cancer and its high-grade precursors, but should be performed in a research setting by multidisciplinary teams in centres with appropriate expertise. Until more evidence supporting these recommendations is available, the benefits, risks and costs of surveillance of pancreatic surveillance need additional evaluation.

\section{INTRODUCTION}

Pancreatic cancer is a deadly disease and early detection is considered the most effective way to improve survival. The International Cancer of the Pancreas Screening (CAPS) Consortium first met in Baltimore in 2011 to establish consensus guidelines for surveillance of individuals with familial and/or inherited risk of developing pancreatic cancer. The 2013 CAPS Consortium guidelines were based on the first decade or so of experience with pancreatic surveillance. ${ }^{1-12}$ More recent evidence includes two studies showing evidence of improved outcomes for high-risk individuals in a pancreatic surveillance programme, highlighting the potential for pancreatic surveillance to affect overall survival. ${ }^{710}$

Individuals with a strong family history and/ or genetic susceptibility have an increased risk of developing pancreatic cancer that manifests over several decades. To help ensure the benefits of pancreatic surveillance, clinicians should select those most likely to benefit, counsel patients on the risks and benefits of surveillance and optimally manage patients with lesions identified by surveillance. The International CAPS Consortium met in Baltimore in April 2018 to update its recommendations for pancreatic surveillance.

\section{METHODS}

\section{Consensus development process}

Conference chairs (Professors Canto, Goggins and Bruno) selected a multidisciplinary team of experts to participate in the guideline update. Guideline development used a modified Delphi approach. ${ }^{13}$ Delphi uses multiple iterations of a questionnaire with feedback, enabling individual reassessment of opinion to generate convergence within the panel. Participants were asked to review literature ahead of an in-person meeting to discuss areas of consensus and controversy and to reach consensus on guideline questions. After the meeting, experts 


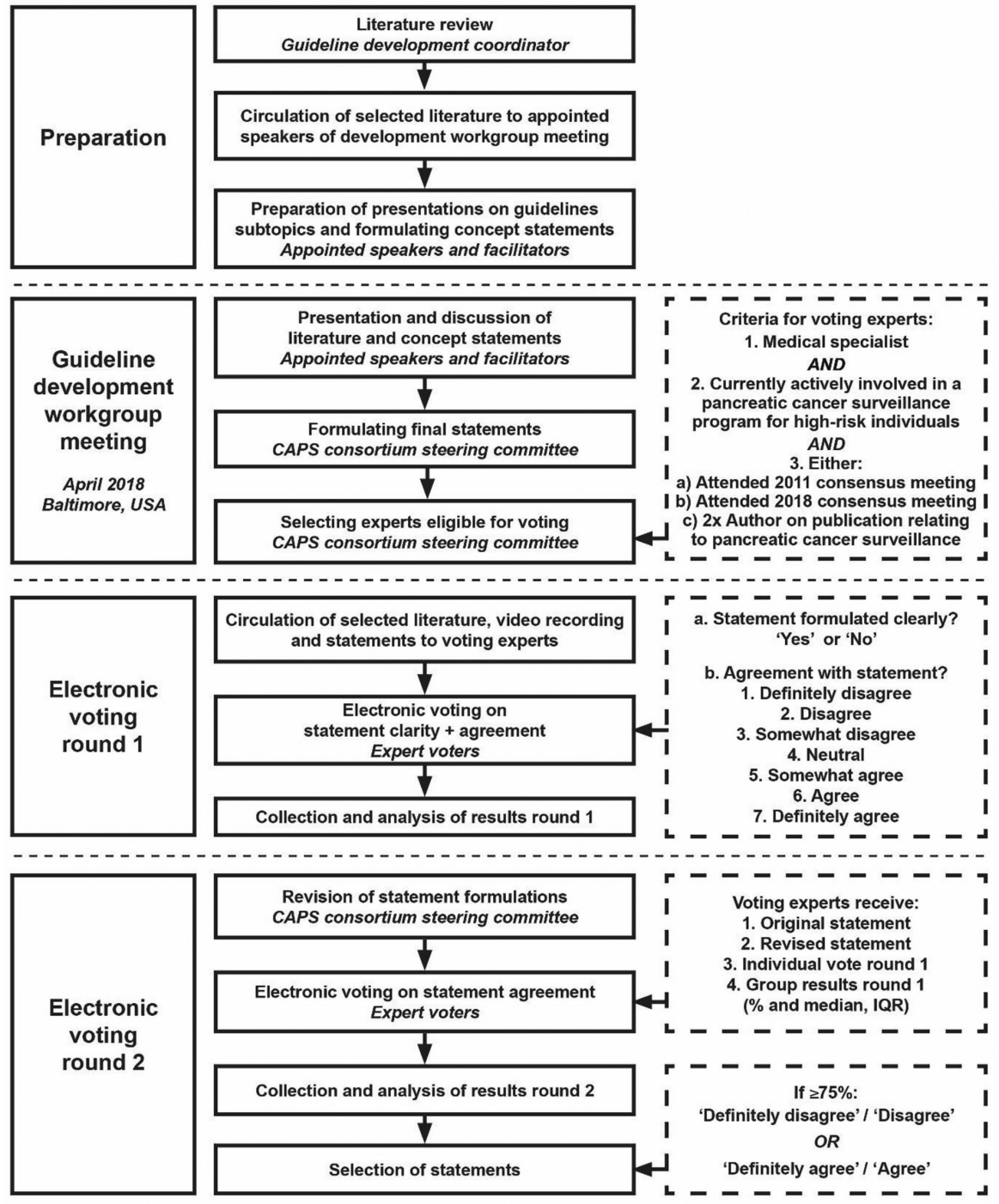

Figure 1 Flow chart of consensus development process. CAPS, Cancer of the Pancreas Screening consortium.

were asked to vote electronically and provide feedback on firstround questions; responses were incorporated into secondround electronic voting (figure 1).

\section{Literature search and development workgroup meeting}

One author (KAO) performed a systematic Medline search for relevant literature published since the 2011 meeting (online supplementary table S1). Speakers and facilitators were selected to discuss major guideline topics focusing on recent literature. Live audio-stream was available for experts not present in person, and the meeting was recorded. After the meeting, the steering committee (MG, KAO, DLC, MIC and MB) formulated voting statements based on 2013 guideline statements, new scientific insights, the meeting presentations and discussions. These statements were incorporated in an electronic survey.

\section{Electronic voting rounds}

International experts within the field of pancreatic cancer surveillance were invited to participate if they met the following criteria: a clinician actively involved in an institutional review board-approved pancreatic cancer surveillance programme for high-risk individuals, who attended either the 2011 or 2018 guideline development workgroup meeting or had been author on two or more scientific publications relating to pancreatic cancer surveillance since 2011. All invited experts were given the recent literature summary and the workgroup meeting video.

In round 1, experts were asked to vote on statements on a seven-point Likert scale, ranging from 'strongly disagree' to 'strongly agree'. They could also opt-out from answering statements if they lacked expertise. After round 1, the steering committee revised statements deemed unclear by $>5 \%$ of respondents.

In round 2, experts voted again and given (1) the original consensus statements and any revisions; (2) first-round voting for each question; and (3) their own voting. Voting was anonymous. Only the guideline coordinator (KAO) had access to voting results.

\section{Statistical analysis, accepting and grading of statements}

First-round group results, including distribution of answers with median and IQR, were given to voters. Statements were accepted as having reached consensus if after second-round voting $\geq 75 \%$ of experts disagreed ('strongly disagree' or 'disagree'), or agreed ('strongly-agree' or 'agree'). Non-votes were not included in consensus tabulations. All statistics were performed using SPSS v22 (IBM, Armonk, New York, USA). Strength of consensus 
Table 1 Definition of high-risk individuals eligible for pancreatic cancer surveillance.

\begin{tabular}{|c|c|c|c|}
\hline Gene mutation & PDAC family history criteria & Agreement & Grade \\
\hline $\begin{array}{l}\text { LKB1/STK11 } \\
\text { (Peutz-Jeghers syndrome) }\end{array}$ & Regardless of family history & $99 \%$ & 1 \\
\hline CDKN2A p16* (FAMMM) & With at least one affected FDR & $99 \%$ & 1 \\
\hline CDKN2A p16* (FAMMM) & Regardless of family history & $77 \%$ & 1 \\
\hline$B R C A 2$ & $\begin{array}{l}\text { If at least one affected FDR, or } \\
\text { at least two affected relativest } \\
\text { of any degree }\end{array}$ & $93 \%$ & 2 \\
\hline PALB2 & If at least one affected FDR & $83 \%$ & 2 \\
\hline $\begin{array}{l}\text { MLH1/MSH2/MSH6 } \\
\text { (Lynch) }\end{array}$ & If at least one affected FDR & $84 \%$ & 2 \\
\hline ATM & If at least one affected FDR & $88 \%$ & 2 \\
\hline$B R C A 1$ & If at least one affected FDR & $69.6 \% \ddagger$ & 3 \\
\hline $\begin{array}{l}\text { Regardless of gene } \\
\text { mutation status }\end{array}$ & $\begin{array}{l}\text { If at least three affected } \\
\text { relativest on the same side of } \\
\text { the family, of whom at least } \\
\text { one is an FDR to the individual } \\
\text { considered for surveillance }\end{array}$ & $97 \%$ & 2 \\
\hline $\begin{array}{l}\text { Regardless of gene } \\
\text { mutation status }\end{array}$ & $\begin{array}{l}\text { If at least two affected } \\
\text { relativest who are FDR to } \\
\text { each other, of whom at least } \\
\text { one is an FDR to the individual } \\
\text { considered for surveillance }\end{array}$ & $93 \%$ & 2 \\
\hline $\begin{array}{l}\text { Regardless of gene } \\
\text { mutation status }\end{array}$ & $\begin{array}{l}\text { If at least two affected } \\
\text { relativest on the same side of } \\
\text { the family, of whom at least } \\
\text { one is an FDR to the individual } \\
\text { considered for surveillance }\end{array}$ & $88 \%$ & 2 \\
\hline
\end{tabular}

* Only encompassing CDKN2A mutations leading to changes in the p16 protein. tWherever relative is stated, this indicates blood relatives only. ¥An additional $20.3 \%$ somewhat agreed with surveillance (total $89.9 \%$ ). $A T M$, ataxia telangiectasia mutated; $B R C A 2$, breast cancer 2; CDKN2A, cyclindependent kinase inhibitor 2A; FAMMM, familial atypical multiple mole melanoma; FDR, first-degree relative; GRADE, Grading of Recommendations, Assessment, Development, and Evaluations; HBOC, hereditary breast and ovarian cancer; LKB1/ STK11, liver kinase B1/serine/threonine kinase 11; Lynch syndrome, $M L H 1$, mutL homolog 1; MSH2, mutS homolog 2; MSH6, mutS homolog 6; PALB2, partner and localizer of BRCA2; PDAC, pancreatic ductal adenocarcinoma.

was based on Grading of Recommendations Assessment, Development and Evaluation (GRADE) ${ }^{14}$ definitions for quality improvement and guideline development: 1 (strong)='definitely do it', 2 (weak)='probably do it', 3 (no recommendation), 4 $($ weak $)=$ 'probably don't do it', and 5 (strong)='definitely don't do it'.

\section{RESULTS}

\section{Participants}

Ninety-one experts met selection criteria and were invited to vote. Eighty-two completed the first round, 76 completed the second round (response rate 84\%). The 76 final responders included 37 gastroenterologists, 16 surgeons, 7 pathologists, 6 radiologists, 5 geneticists, 3 oncologists, and two epidemiologists, from 11 countries and four continents; 70 (92\%) worked in a university hospital setting. They had practised their profession for a median of 22 (IQR 15) years, and had been involved in a pancreatic cancer surveillance programme for a median of 10 (IQR 12) years.

\section{Recommendation statements}

A summary of the statements that reached consensus is provided in tables 1 and 2 . All voting statements and results are provided in online supplementary table S2. A summary of the main consensus recommendations is provided in table 3 .

\section{Who should be screened?}

Age, family history and germline mutation status are the major criteria for determining eligibility for pancreatic surveillance. The number of first- and second-degree relatives with pancreatic cancer can be used to quantify pancreatic cancer risk. ${ }^{15}$ For example, the estimated lifetime risk of developing pancreatic cancer for an individual with two first-degree relatives with pancreatic cancer is $\sim 8 \% .^{15} 16$ Family history of pancreatic cancer is also a risk factor for patients identified as having incidentally detected pancreatic cysts. ${ }^{17}$ Current surveillance recommendations for a family history (generally in one blood relative) are the same as for those without a family history. ${ }^{18} 19$

Consensus on family history recommendations for pancreatic surveillance (ie, having at least one first-degree relative and one second-degree relative with pancreatic cancer) were the same as in the 2013 guidelines. Obtaining a comprehensive cancer family history from newly diagnosed patients with pancreatic cancer can help to identify family members who may benefit from surveillance. The average lifetime risk of developing pancreatic cancer ( $~ 1$ in 64 in the USA) is too low for population-based screening. ${ }^{20} 21$

\section{Germline mutation carriers}

Pancreatic surveillance is recommended for carriers of germline deleterious variants in cancer susceptibility gene, ${ }^{22-26}: B R C A 2$, ATM, BRCA1, PALB2, CDKN2A, STK11, MLH1 and MSH2. Recommendations for age and family history vary by gene. Surveillance for CDKN2A and STK11 (Peutz-Jegher syndrome) mutation carriers is recommended irrespective of patients' family history of pancreatic cancer, because of their high lifetime risk. Since the previous consensus, ATM mutation carriers have been added to the list recommended for surveillance. For carriers of mutations in ATM, BRCA2 and PALB2, the consensus among experts was to recommended surveillance for mutation carriers who have a blood relative with pancreatic cancer. Consensus on family history criteria for BRCA1 mutation carriers was not reached (table 1), but consensus was reached for recommending that BRCA1 mutation carriers undergo surveillance (online supplementary table S2).

Surveillance is recommended for patients with hereditary pancreatitis, with most experts recommending age 40 or 20 years after the first pancreatitis attack (online supplementary table S2), irrespective of gene status. The pancreatitis susceptibility genes, PRSS1, CPA1 and CTRC, are associated with significantly increased risk of developing pancreatitis. ${ }^{27-30}$ Deleterious variants in CPA1 and CPB1 associated with pancreatic cancer risk may not always progress through a clinical syndrome of pancreatitis. $^{31}$

Deleterious variants in the known pancreatic cancer susceptibility genes account for $\sim 10-20 \%$ of the familial clustering of pancreatic cancer. ${ }^{2632} 33$ Deleterious variants have also been reported in $\sim 5-10 \%$ of patients with apparently sporadic pancreatic cancer. ${ }^{34-39}$ These variants also confer risk for other cancers. ${ }^{40}$ Therefore, germline testing should be considered for individuals eligible for pancreatic cancer surveillance. ${ }^{4142}$ Recent National Comprehensive Cancer Network (NCCN) guidelines recommend offering gene testing for patients with newly diagnosed pancreatic ductal adenocarcinoma; this recommendation did not reach consensus among CAPS experts (online supplementary table S2). American Society of Clinical Oncology guidelines 
Table 2 Statements that reached consensus

Statement
At what age should pancreatic surveillance begin?
1. For patients with a familial risk (no known germline mutations or PJS),
should begin by the age of...
45 years or 10 years younger than the youngest relative with PDAC
50 years or 10 years younger than the youngest relative with PDAC
55 years or 10 years younger than the youngest relative with PDAC

2. For germline mutation carriers (excluding PJS), screening should begin 5 years earlier than for high-risk individuals with defined familial pancreatic cancer

3. For patients with PJS, screening should begin at least by the age of..

- 30 years or 10 years younger than the youngest relative with PDAC

- 35 years or 10 years younger than the youngest relative with PDAC

- 40 years or 10 years younger than the youngest relative with PDAC

4. New-onset diabetes in a high-risk individual should lead to initiation of screening, regardless of age.

How should high-risk individuals be screened?

5. Baseline pancreatic screening tests should include (multiple answers allowed)

- EUS

MRI/MRCP

S), screening

grade

$\mathrm{CT}$

- Abdominal ultrasound

6. Follow-up pancreatic screening tests should include (multiple answers allowed)

$\rightarrow$ EUS

- MRI/MRCP

- CT

- Abdominal ultrasound

7. CA19-9 should be used as an additional surveillance test for individuals with worrisome features on imaging

8. Routine testing for diabetes mellitus with fasting blood glucose and/or haemoglobin

A1c should be performed.

Surveillance questions

9. In the absence of pancreatic abnormalities, the recommended surveillance interval is 12 months

10. For patients with small $(<1 \mathrm{~cm})$, non-functioning neuroendocrine tumours, the recommended surveillance interval is 12 months

11. For patients with low-risk findings (ie, pancreatic lobulation or a cyst without worrisome features), the recommended surveillance interval is 12 months

12. For CDKN2A p16 mutation carriers with newly detected pancreatic abnormalities that are concerning but do not lead to surgery (mild MPD dilation, stricture without mass), repeat imaging should be performed within 3-6 months

13. A diagnosis of new-onset diabetes* in an HRI under surveillance, prompts immediate investigations

14. Smoking status does not affect the surveillance interval

$10.3 \%$

$67.6 \%$

$22.1 \%$

$74.7 \%$

$14.9 \%$

$17.9 \%$

$67.2 \%$

$82.4 \%$

15. When a cystic lesion with worrisome features (ie, mural nodule, solid component, duct dilation, etc) is detected, EUS-FNA should be performed.

16.When a solid lesion is detected, CT should be performed

17. At detection of a solid lesion, EUS-FNA should be performed...

- Always

- If $\geq 5 \mathrm{~mm}$

- If $\geq 10 \mathrm{~mm}$

- Never

18. When a solid lesion of uncertain significance is newly detected and the patient is not referred for surgery, imaging should be repeated after 3 months

19. Standardised nomenclature should be used to define chronic pancreatitis-like abnormalities

20. When an asymptomatic MPD stricture with an associated suspicious mass is detected...

- EUS-FNA should be performed

- Surgery should be performed

21. When an asymptomatic MPD stricture of unknown aetiology (without a mass) is detected...

- CT should be performed

- EUS-FNA should be performed

22. When a patient with an MPD stricture is not referred for surgery, repeat imaging should be performed within 3 months

\begin{tabular}{|c|c|}
\hline $86.8 \%$ & 2 \\
\hline $92.1 \%$ & 2 \\
\hline $19.7 \%$ & 4 \\
\hline $2.6 \%$ & 5 \\
\hline $89.5 \%$ & 2 \\
\hline $89.5 \%$ & 2 \\
\hline $15.8 \%$ & 4 \\
\hline $1.3 \%$ & 5 \\
\hline $76.5 \%$ & 2 \\
\hline $76.1 \%$ & 2 \\
\hline $90.4 \%$ & 2 \\
\hline $82.6 \%$ & 2 \\
\hline $88.6 \%$ & 2 \\
\hline $98.5 \%$ & 2 \\
\hline $90.3 \%$ & 2 \\
\hline $76.8 \%$ & 2 \\
\hline $84.3 \%$ & 2 \\
\hline $95.7 \%$ & 1 \\
\hline $70.1 \%$ & 2 \\
\hline $19.4 \%$ & 1 \\
\hline $4.5 \%$ & 1 \\
\hline $6.0 \%$ & 5 \\
\hline $91.2 \%$ & 1 \\
\hline $98.6 \%$ & 2 \\
\hline $75.7 \%$ & 1 \\
\hline $81.2 \%$ & 2 \\
\hline $86.6 \%$ & 1 \\
\hline $77.9 \%$ & 1 \\
\hline $98.5 \%$ & 1 \\
\hline
\end{tabular}




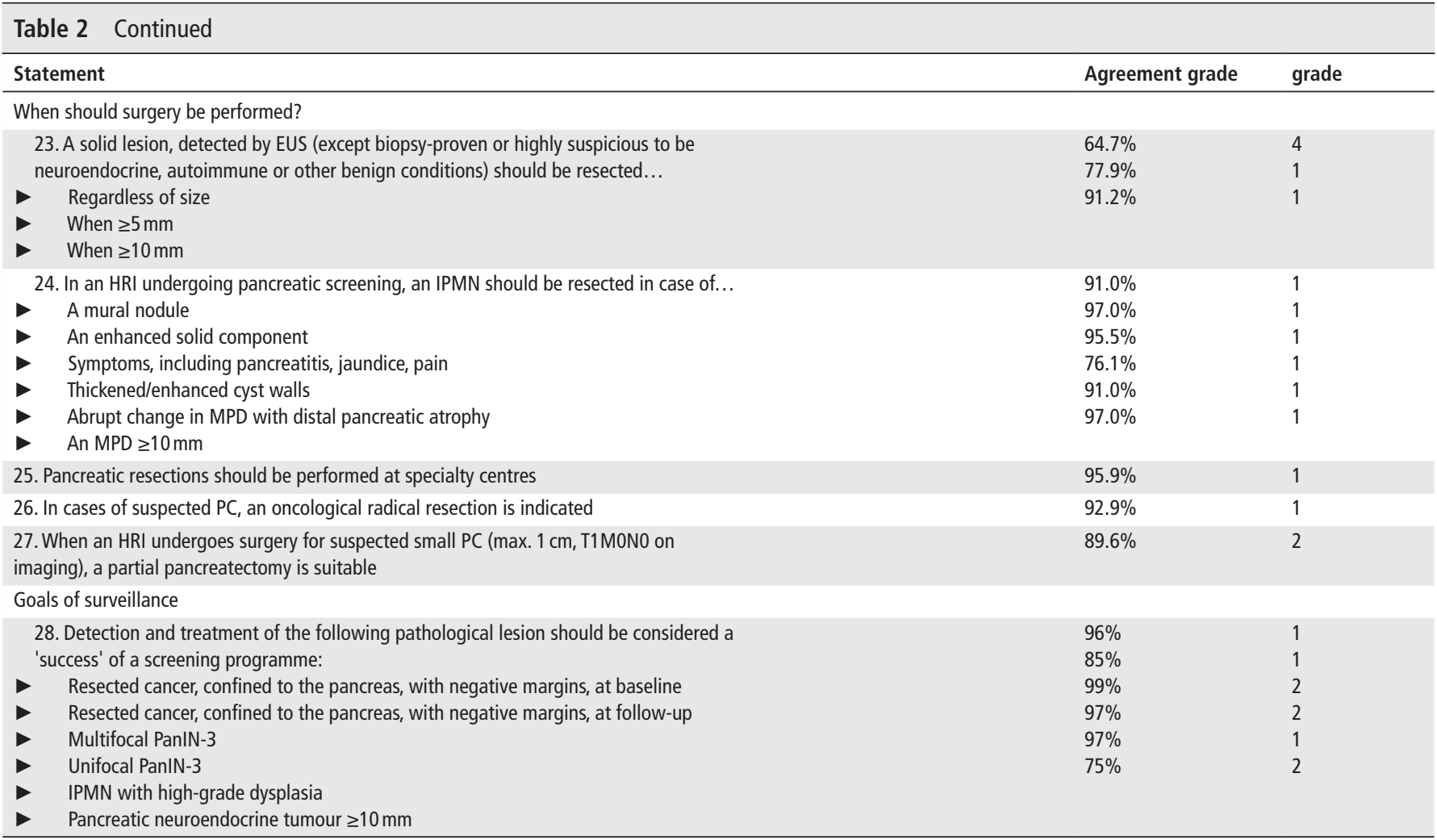

CA19-9, carbohydrate antigen 19-9; CDKN2A, cyclin-dependent kinase inhibitor 2A; CT, computed tomography; EUS, endoscopic ultrasound; FNA, fine-needle aspiration; HRI, high-risk individual; IPMN, intraductal papillary mucinous neoplasm; MPD, main pancreatic duct; MRI/MRCP, magnetic resonance imaging/magnetic retrograde cholangiopancreatography; PanIN-3, pancreatic intraepithelial neoplasia-3; PC, pancreatic ductal adenocarcinoma; PDAC, pancreatic ductal adenocarcinoma; PJS, Peutz-Jeghers syndrome.

also consider the role of gene testing for patients with pancreatic cancer. ${ }^{43}$ The average lifetime risk of developing pancreatic cancer has been estimated in prospective studies for carriers of deleterious variants in BRCA2, BRCA1, CDK2NA, PRSS1, MLH1 and MSH2, $2252944-46$ and odds of developing pancreatic cancer from case/control analysis for ATM, PALB2 and TP53. ${ }^{35}$ Many individuals undergo gene testing because a germline mutation was identified in a blood relative who developed cancer. The risk of pancreatic cancer in $A T M / B R C A / P A L B 2$ mutation carriers without a pancreatic cancer family history is not well defined. A study of BRCA mutation carriers found no difference in pancreatic cyst prevalence by family history; although the authors suggested pancreatic surveillance is appropriate for BRCA mutation carriers irrespective of family history, more evidence on this question is needed. ${ }^{47}$ Although family history remains an important risk assessment tool, ${ }^{48}$ pedigrees are often small and family histories incomplete. Further research is needed to better define how family history of pancreatic cancer in mutation carriers influences their risk of developing the disease.

\section{At what age should pancreatic surveillance begin?}

For individuals who meet familial risk criteria (without a defined genetic mutation) the consensus was that surveillance should begin at age 50 or later; but some experts thought surveillance should begin at 50 , others at age 55 . Most pancreatic surveillance programmes lower the age at which surveillance is initiated for individuals with a first-degree relative with young-onset pancreatic cancer $($ age $<50) .{ }^{49}$ For mutation carriers, with a deleterious germline variant, the recommended age to initiate surveillance is generally age 50 (BRCA2, ATM, PALB2), though some groups would start surveillance at age 45 and earlier still for the higher-risk genes; surveillance from age 40 is recommended for CDKN2A mutation carriers; $16 \%$ of p16-Leiden mutation carriers with pancreatic cancer were diagnosed at age $<45^{50}$ and at age $30-40$ for those with Peutz-Jegher syndrome. ${ }^{3}$ When to initiate pancreatic surveillance for these mutation carriers did not reach consensus (online supplementary table S2). To date, most pancreatic cancers in high-risk individuals with familial risk only (ie, no known susceptibility gene mutation) under surveillance are diagnosed after age $55 .^{10}$ The average age of pancreatic cancer diagnosis among individuals with a family history of pancreatic cancer is younger than for those with no family history, and mutation carriers who develop pancreatic cancer are diagnosed at a slightly younger age ( $\sim 3-5$ years) than those with sporadic forms of the disease. ${ }^{34-36}$ The average age for diagnosis of pancreatic cancer is slightly younger in smokers (by several years) than in non-smokers. ${ }^{5152}$ The relative risk of pancreatic cancer among smokers is not considered sufficiently high to recommend surveillance in the absence of other risk factors. There was no consensus that the age at which surveillance begins should be modified for high-risk individuals who smoke. As pancreatic cancer risk factors become better defined, it should become possible to provide more accurate individualised risk assessment that can be used to provide personalised recommendations for pancreatic surveillance. ${ }^{53}$

\section{What tests should be used for pancreatic surveillance?}

Most pancreatic surveillance protocols for high-risk individuals use pancreatic imaging with MRI/magneticretrograde cholangiopancreatography (MRCP) and/or endoscopic ultrasound (EUS), with pancreatic-protocol CT reserved for individuals unable to have MRI or EUS. The preference for EUS and MRI/ 
Table 3 Summary of the main recommendations of the 2019 International Cancer of the Pancreas Surveillance (CAPS) Consortium

\begin{tabular}{|c|c|c|}
\hline \multicolumn{3}{|l|}{ Who? } \\
\hline \multicolumn{3}{|c|}{$\begin{array}{l}\text { All patients with Peutz-Jeghers syndrome (carriers of a germline } L K B 1 / S T K 11 \text { gene mutation) } \\
\text { All carriers of a germline CDKN2A mutation } \\
\text { Carriers of a germline BRCA2, BRCA1, PALB2, ATM, MLH1, MSH2, or MSH6 gene mutation with at least one affected first-degree blood relative } \\
\text { Individuals who have at least one first-degree relative with pancreatic cancer who in turn also has a first-degree relative with pancreatic cancer (familial pancreatic cancer } \\
\text { kindred) }\end{array}$} \\
\hline \multicolumn{3}{|l|}{ When (at what age)? } \\
\hline \multicolumn{3}{|c|}{ - Age to initiate surveillance depends on an individual's gene mutation status and family history } \\
\hline \multicolumn{2}{|l|}{$\begin{array}{l}\text { Familial pancreatic cancer kindred } \\
\text { (without a known germline mutation) }\end{array}$} & $\begin{array}{l}\text { Start at age } 50 \text { or } 55^{*} \text { or } 10 \text { years younger than the } \\
\text { youngest affected blood relative }\end{array}$ \\
\hline \multicolumn{3}{|c|}{$\begin{array}{l}\text { Mutation carriers: For CDKN2At, Peutz-Jegher syndrome, start at age } 40 ; B R C A 2, A T M, P A L B 2 B R C A 1, M L H 1 / M S H 2 \text { start at age } 45 \text { or } 50 \text { or } 10 \text { years younger than youngest } \\
\text { affected blood relative }\end{array}$} \\
\hline \multicolumn{3}{|c|}{ There is no consensus on the age to end surveillance } \\
\hline \multicolumn{3}{|l|}{ How? } \\
\hline At baseline & \multicolumn{2}{|c|}{ - MRI/MRCP+EUS + fasting blood glucose and/or HbA1c } \\
\hline During follow-up & \multicolumn{2}{|c|}{$\begin{array}{l}\text { Alternate MRI/MRCP and EUS (no consensus if and how to alternate) } \\
\text { Routinely test fasting blood glucose and/or HbA1c }\end{array}$} \\
\hline \multirow[t]{2}{*}{ On indication } & $\begin{array}{l}\text { Serum CA 19-9 } \\
\text { EUS-FNA only for }\end{array}$ & $\begin{array}{l}\text { If concerning features on imaging } \\
\text { Solid lesions of } \geq 5 \mathrm{~mm} \\
\text { Cystic lesions with worrisome features } \\
\text { Asymptomatic MPD strictures (with or without mass) }\end{array}$ \\
\hline & CT only for & $\begin{array}{l}\text { Solid lesions, regardless of size } \\
\text { Asymptomatic MPD strictures of unknown aetiology } \\
\text { (without mass) }\end{array}$ \\
\hline \multicolumn{3}{|l|}{ Intervals and surgery } \\
\hline 12 Months & \multicolumn{2}{|c|}{$\begin{array}{l}\text { If no abnormalities, or only non-concerning abnormalities } \\
\text { (eg, pancreatic cysts without worrisome features) }\end{array}$} \\
\hline 3 or 6 Months & \multicolumn{2}{|c|}{$\begin{array}{l}\text { If concerning abnormalities for which immediate surgery is not indicated } \\
\text { (see figure } 2 \text { for details) }\end{array}$} \\
\hline Surgery & \multicolumn{2}{|c|}{ If positive FNA and/or a high suspicion of malignancy on imaging (see figure 2 for details) } \\
\hline \multicolumn{3}{|c|}{ When surgery is indicated, perform an oncological radical resection at a specialty centre } \\
\hline \multicolumn{3}{|l|}{ Goals } \\
\hline The goal of surveillance is to detect anc & g pathological lesions & $\begin{array}{l}\text { Stage I pancreatic cancer, confined to the pancreas, } \\
\text { resected with negative margins } \\
\text { Pancreatic cancer precursor lesions with high-grade } \\
\text { dysplasia (PanIN or IPMN) }\end{array}$ \\
\hline
\end{tabular}

${ }^{*}$ Consensus as to when to start surveillance was not reached.

tLiterature-based recommendation.

ATM, ataxia telangiectasia mutated; BRCA2, breast cancer 2; CDKN2A, cyclin-dependent kinase inhibitor 2A; CT, computed tomography; EUS, endoscopic ultrasound; FNA, fine-needle aspiration; HbA1c, hemoglobin A1c; IPMN, intraductal papillary mucinous neoplasm; $M L H 1$, mutL homolog 1; MPD, main pancreatic duct; MRI/MRCP, magnetic resonance imaging/magnetic retrograde cholangiopancreatography; $M S H 2$, mutS homolog 2; MSH6, mutS homolog 6; PALB2, partner and localizer of BRCA2; PanIN, pancreatic intraepithelial neoplasia; STK11, serine/ threonine kinase 11.

MRCP rather than CT is based on their superiority at detecting subcentimetre pancreatic cysts, and avoidance of ionising radiation. ${ }^{1}$ Subcentimetre pancreatic cysts are detected in up to $50 \%$ of high-risk individuals, depending on the age of the cohort. ${ }^{1054}$ However, pancreatic cysts have low malignant potential and although their detection can help risk stratification, the primary responsibility of pancreatic imaging tests is to detect pancreatic cancers. In this respect, EUS may be better for detecting small pancreatic ductal adenocarcinomas, although this evidence is based on studies of small numbers of individuals ${ }^{55}$; some centres use EUS as the primary test for pancreatic surveillance. EUS diagnostic yield is highly operator dependent. ${ }^{56}$ EUS has previously been shown to be better at detecting small neuroendocrine tumours. ${ }^{57}$ EUS also identifies subtle non-specific parenchymal abnormalities, which in a high-risk setting may represent the effects of pancreatic intraepithelial neoplasia (PanIN) with associated lobulocentric atrophy. ${ }^{58-60}$

Pancreatic-protocol CT can accurately detect early-stage pancreatic cancers and performs similarly to MRI in detecting evidence of cancer/high-grade dysplasia associated with intraductal papillary mucinous neoplasms (IPMN). ${ }^{61}$ In addition, CT can, in principle, also be used to quantify changes in abdominal fat and lumbar muscle mass with the emergence of pancreatic cancer. ${ }^{62} 63$ Observation of this early wasting could help to detect early pancreatic cancers, although this approach has not been tested in prospective studies. The availability of deep learning and advanced radiomics protocols may help radiologists to identify and quantify subtle abnormalities in the pancreas by CT. ${ }^{6465}$

Based on current evidence, the consensus among experts is that MRI/MRCP and EUS should be the first-line tests for pancreatic surveillance, in part because of the cumulative radiation exposure with frequent CT, but developments in low-dose CT imaging may necessitate re-evaluation of the role of CT in surveillance. One European study examined the diagnostic yield of performing MRI/ MRCP annually with EUS or limiting EUS to every third year unless there are significant changes in MRI scans. The authors found no significant difference in the diagnostic yield among the different surveillance protocols, ${ }^{66}$ although a larger sample size and longer follow-up would be required to definitively answer this question. Less expensive, short-protocol MRI has been evaluated for cyst 
surveillance. ${ }^{67}$ Some Japanese centres have evaluated abdominal ultrasound as a screening modality, ${ }^{68}$ as detailed pancreas sonographic images are feasible in thin individuals, but there was consensus that abdominal ultrasound should not be a first-line test for pancreatic surveillance.

The experts also considered the role of CA19-9 testing. Although the role of CA19-9 testing has not been studied in high-risk individuals with familial/genetic risk, its diagnostic performance characteristics have been extensively studied. ${ }^{69-71}$ CA19-9 could have diagnostic value in individuals in whom the pre-test probability of pancreatic cancer is significant, although this question requires further investigation. For this reason, there was consensus that CA19-9 testing should be performed when there is concern about the possibility of pancreatic cancer, such as when worrisome features are found on pancreatic imaging.

Experts also reached consensus that glucose testing (fasting glucose or HbA1C) to detect new-onset diabetes was reasonable for high-risk individuals. There was also consensus that the emergence of new-onset diabetes in a high-risk individual should prompt additional investigation. Population guidelines recommend fasting glucose or $\mathrm{HbA} 1 \mathrm{c}$ testing for individuals with risk factors for diabetes such as overweight or obesity, ${ }^{72}$ although there are concerns about the potential to overtreat individuals with pre-diabetes. Epidemiological studies show that $0.4 \%$ to $0.8 \%$ of patients with new-onset diabetes aged $\geq 50$ will be diagnosed with pancreatic cancer within 3 years. ${ }^{62}{ }^{73-75} \mathrm{~A}$ model incorporating weight loss, age and trend in glucose level can help to identify patients with new-onset diabetes more likely to have pancreatic cancer ${ }^{76}$; other models incorporating additional parameters are being evaluated. ${ }^{77}$ One study estimated the average glucose level for a given tumour size, predicting that when glucose levels reach diabetic levels $(126 \mathrm{mg} / \mathrm{dL})$, pancreatic tumour volume is $\sim 2-8 \mathrm{~mL}$ ( diameter of $1.6-2.5 \mathrm{~cm}$ ) ${ }^{76}$ There is no direct evidence that glucose monitoring is of additional value for improving detection of pancreatic cancer for individuals undergoing regular pancreatic imaging. Nonetheless, given the higher risk of pancreatic cancer in high-risk individuals compared with the general population, the consensus was that new-onset diabetes in a high-risk individual should prompt further testing for the presence of pancreatic cancer.

Experts discussed circulating tumour DNA (ctDNA) and its potential to contribute to pancreatic surveillance. ${ }^{78-80}$ CtDNA testing is beginning to emerge as a clinical test ${ }^{81}$; further studies are needed to define its role for patients under pancreatic surveillance. Other biomarker tests are also undergoing evaluation for their potential for early detection, ${ }^{6382-84}$ but more study is needed to determine their diagnostic performance.

The experts recognised that many high-risk individuals meeting criteria for pancreatic surveillance (particularly mutation carriers) are at increased risk of developing other cancers; these individuals should undergo surveillance for other cancers tailored to their germline mutation status and cancer family history.

\section{Surveillance questions}

There was consensus that patients with normal pancreata, or without concerning lesions, should undergo annual pancreatic imaging surveillance. Surveillance of high-risk individuals occasionally identifies small $(<1 \mathrm{~cm})$ pancreatic neuroendocrine tumours (PanNETs) $)^{1-11}$ although it is not certain if these lesions are more common in this population. Most incidentally detected PanNETs have low malignant potential. ${ }^{85}$ There was consensus that patients with small $(<1 \mathrm{~cm}$ diameter) PanNETs can also undergo annual surveillance detection and that treatment of PanNETs $(>1 \mathrm{~cm})$ could be considered a success of surveillance. However, recent studies report small $(<2 \mathrm{~cm})$ PanNETs with low-risk characteristics on biopsy (eg, low Ki-67) can be safely followed up. ${ }^{86-88}$ Current neuroendocrine neoplasms guidelines recommend surveillance of asymptomatic non-functional low-risk (by grade, Ki-67 by EUSfine-needle aspiration) PanNETs $(2 \mathrm{~cm}){ }^{88}$

Although patients in a high-risk programme commonly have pancreatic abnormalities (depending on age and other riskfactors, up to $50 \%$ will have pancreatic cysts; many also have subtle non-specific EUS parenchymal abnormalities), only a minority will develop concerning lesions. There was consensus that annual surveillance is appropriate for those with these abnormalities (figure 2). Furthermore, there was consensus that CDKN2A mutation carriers with concerning pancreatic abnormalities that do not lead to immediate surgery (eg, mild main pancreatic duct dilation, stricture without mass) should undergo additional testing such as EUS/fine-needle aspiration, and if they do not proceed to surgery after multidisciplinary review, should undergo close follow-up imaging in 3-6 months.

The predicted progression rate suggests that stage I pancreatic cancers can progress to stage IV disease within 1 year, ${ }^{89}$ which may explain why interval pancreatic cancers are occasionally diagnosed despite annual surveillance, even in the absence of concerning lesions (worrisome features or solid lesions) ${ }^{18} 19$ on prior scans.

Few studies have evaluated factors that influence compliance with long-term pancreatic surveillance; one such study found that many high-risk individuals drop out of regular surveillance. ${ }^{90}$ Factors affecting long-term compliance with surveillance require further study.

\section{When should surgery be performed?}

Many factors are considered when deciding if surgical resection is appropriate for patients with concerning imaging findings, including a patient's estimated risk of pancreatic cancer based on their gene mutation status, family history, operative risk, comorbidities, life expectancy and compliance with surveillance. Decision-making is best undertaken by an experienced, expert multidisciplinary team. There was consensus that highrisk individuals should undergo pancreatic resection for broadly similar indications to individuals without known familial/genetic risk, based on established guidelines-for example, those with worrisome features. ${ }^{18} 199192$ Thus, generally, surgical resection in a patient with multifocal pancreatic cysts should manage the dominant, worrisome lesion. There was consensus that patients with solid lesions of indeterminate pathology and $>5 \mathrm{~mm}$ should undergo pancreatic resection if additional evaluation does not yield a definitive preoperative diagnosis.

Some high-risk individuals develop multiple precursors throughout their pancreas, and those who undergo pancreatic resection for IPMN can have concomitant high-grade PanIN. ${ }^{59}$ This raises the question of whether resection criteria for high-risk individuals should include less concerning lesions than for those with sporadic disease, or if total pancreatectomy should be considered. There is no evidence to support this approach unless there are concerning lesions affecting multiple regions of the gland. Total pancreatectomy is a major operation, although studies have reported that morbidity and mortality are similar to those of Whipple operations, and diabetes-related mortality, is quite rare. ${ }^{93} 94$ There was also no consensus that surgical resection was indicated for less worrying lesions, such as suspected IPMN of $2 \mathrm{~cm}$ or with mild main pancreatic duct dilatation.

Consensus was also reached that the operative approach to a resectable pancreatic cancer should be the same for high-risk 


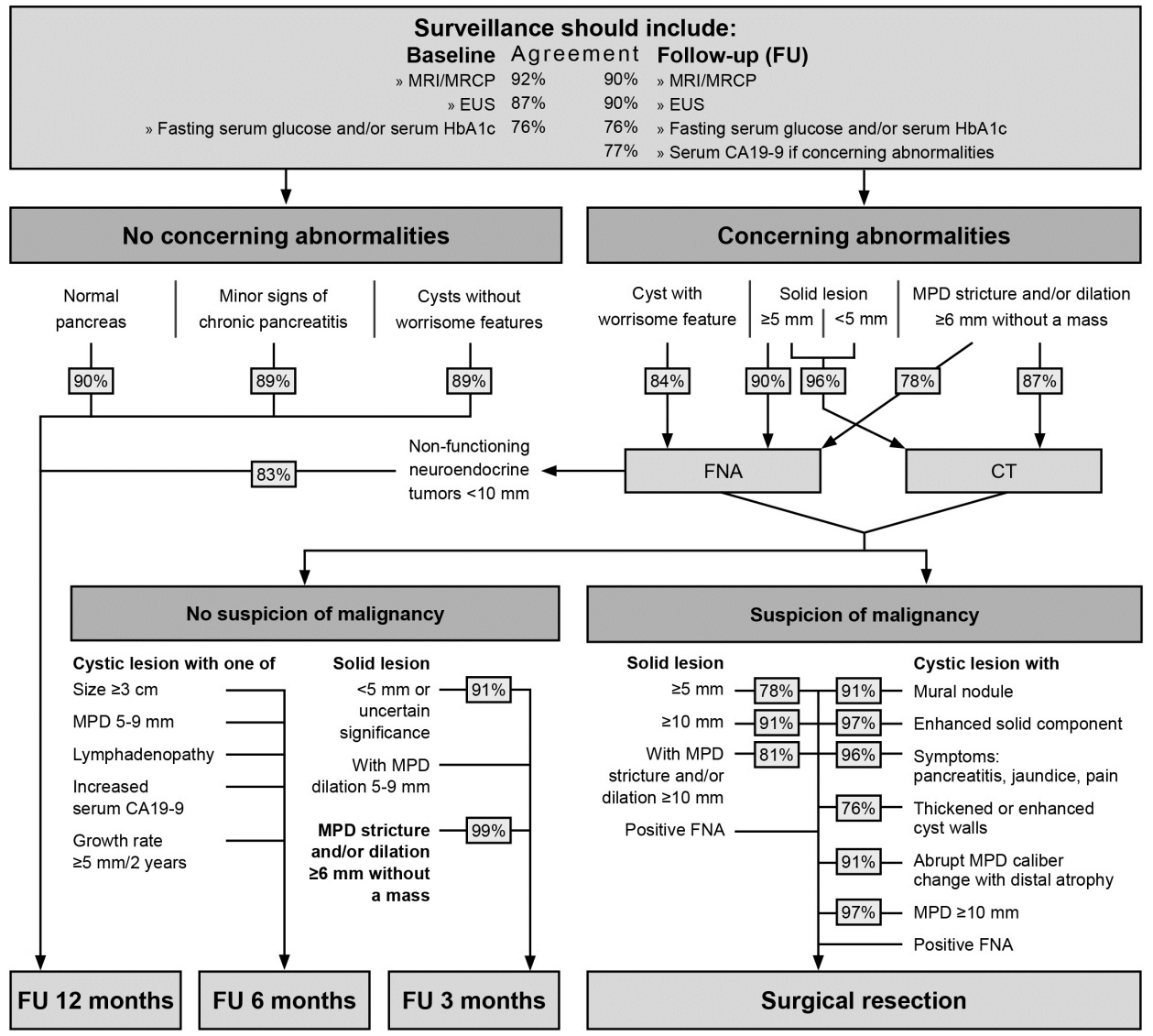

Figure 2 Decision flow-chart for the management of pancreatic abnormalities found during surveillance. EUS, endoscopic ultrasound; FNA, fineneedle aspiration; MPD, main pancreatic duct; MRCP, magnetic retrograde cholangiopancreatography.

individuals and those with sporadic pancreatic cancer. Patients with sporadic IPMN who have had partial pancreatectomy have a $5-10 \%$ risk of developing pancreatic cancer $^{95-98}$; ongoing surveillance of these individuals is needed. Studies have identified factors associated with metachronous disease. ${ }^{97} 98$ In some cases, metachronous disease represents re-emergence of a previously resected IPMN, raising the possibility that precancerous cells might spread through the main pancreatic duct. ${ }^{98-100}$ In germline mutation carriers, particularly those at highest risk of pancreatic cancer, the possibility of multiple primary cancers should be considered. ${ }^{101}$

\section{What are the goals of surveillance?}

The primary goal of pancreatic surveillance is to prevent death from pancreatic cancer and prevent its emergence by identifying and treating precursor lesions. As with the first CAPS consensus guideline, there was consensus that the main pathological targets of surveillance are stage I pancreatic cancers and precursors with high-grade dysplasia either in PanIN or IPMN (online supplementary table S3). Since the last consensus meeting, the classification of pancreatic precursors has been slightly revised. ${ }^{102}$

Published studies of surveillance programmes reveal evidence of downstaging of pancreatic cancers, with most pancreatic cancers diagnosed as stage IIB or stage I. ${ }^{710}$ The detection and management of high-grade dysplasia in PanIN and IPMN remains an important goal of surveillance; these lesions are not only more commonly detected by pancreatic imaging, they are more likely to have pancreatic precursor lesions than in patients without such a family history. ${ }^{103}$
The imaging characteristics of IPMN can be useful in identifying evidence of high-grade dysplasia within IPMN, but this is not the case for PanIN, most of which are microscopic lesions that cannot be identified with available technologies. Most pancreatic ductal adenocarcinomas are thought to arise from PanIN. This is thought to be true for patients with sporadic pancreatic cancers and also for those with a familial/ inherited susceptibility to develop pancreatic cancer. Most pancreatic cancers from such individuals have genetic signatures consistent with PanIN origin, ${ }^{26}$ and pancreatic cancers detected during surveillance often arise in areas of the gland separate from pancreatic cysts. ${ }^{95} 104$ Indeed, many pancreatic cancers associated with IPMN are genetically distinct from the IPMN. ${ }^{105}$ Since PanIN generally do not cause specific imaging abnormalities, high-grade PanIN (previously known as PanIN-3) is diagnosed only by surgical pathology review of pancreatic resections undertaken for other concerning imaging findings. In some cases, evidence of pancreatic neoplasia can be inferred by the presence of mutations detected in secretinstimulated pancreatic fluid samples, ${ }^{104} 106$ and multifocal PanIN lesions by imaging findings of lobulocentric atrophy, ${ }^{59}$ but further investigation is needed to determine the value of these tests for patients under pancreatic surveillance.

\section{Areas for future research}

Emerging technologies such as CT detection of muscle and fat wasting as well as subtle changes in the pancreas using deep learning have yet to be applied to the high-risk setting. Similarly, the value of glucose monitoring in detecting new-onset diabetes for patients 
already undergoing routine pancreatic imaging is not known. The development of non-invasive blood tests, such as tests for ctDNA, provides hope that these will eventually improve the early detection of pancreatic cancer. The emergence of interval (ie, presenting before their annual surveillance) advanced-stage pancreatic cancers in some patients under regular pancreatic imaging suggests that biological characteristics, such as early lymph node metastases and venous invasion even with small cancers, ${ }^{107}$ make early detection efforts particularly challenging. The main factors used in clinical practice to assess the risk of pancreatic cancer in high-risk individuals remain family history, gene mutation status, age and pancreatic imaging abnormalities. Other known factors, such as diabetes and metabolic syndrome markers, smoking status, other cancer family history, gene variants identified through genome-wide meta-analysis, ${ }^{108}$ and circulating biomarkers that predict future risk, ${ }^{109}$ could help to improve risk stratification, particularly if models could be developed and validated.

Cost-effectiveness models of pancreatic surveillance have been reported. One recent paper estimated that MRI is more cost-effective in the USA overall, with EUS more cost-effective for highest-risk individuals (relative risk $>20$ ) $^{110}$; cost-effective model results depend on cost estimates and MRI and EUS costs vary considerably. Ultimately, pancreatic surveillance programmes need to demonstrate better evidence that survival from pancreatic cancer can be improved by surveillance or even that the detection and treatment of high-grade dysplasia can lower the incidence of pancreatic cancer. ${ }^{111}$ Indeed, the US Preventive Services Task Force recommended that pancreatic screening should not be carried out, ${ }^{21} 112113$ although it excluded the study by Vasen et al, ${ }^{7}$ because it focused on mutation carriers and completed its literature review before the recent CAPS study was published. ${ }^{10}$ These two studies show that pancreatic surveillance of high-risk individuals can lead to downstaging of pancreatic cancers diagnosed. Such downstaging is associated with better survival compared with historical controls, particularly when surveillance detects stage I cancers. The need to evaluate long-term outcomes necessitates pancreatic surveillance be undertaken in academic settings. Efforts to implement a pancreatic surveillance programme need to be balanced with its costs. This is a difficult balance to achieve since the harms of overdiagnosis can take many years to become evident, as is the case for other cancers. ${ }^{114-116}$ The evaluation of long-term outcomes of high-risk individuals participating in pancreatic surveillance programmes, 79596117 including the potential for harm, should continue.

\footnotetext{
Author affiliations

'Pathology, Medicine Oncology, Johns Hopkins University, Baltimore, Maryland, USA ${ }^{2}$ Gastroenterology and Hepatology, Erasmus University Medical Center, Rotterdam, The Netherlands

${ }^{3}$ Medicine, University of Pittsburgh Medical Center, Pittsburgh, Pennsylvania, USA

${ }^{4} \mathrm{GI}$ Cancer Genetics and Prevention Program, Medical Oncology, Dana Farber Cancer Institute, Boston, Massachusetts, USA

${ }^{5}$ Department of Surgery, Division of Surgical Oncology, Denver, Colorado, USA

${ }^{6}$ Division of Visceral, Thoracic and Vascular Surgery, University of Marburg, Marburg,

Germany

${ }^{7}$ Department of Surgey, University of Verona, Verona, Italy

${ }^{8}$ Medical Oncology, Hospital Ramón y Cajal, Madrid, Spain

${ }^{9}$ Medicine, Yale University School of Medicine, New Haven, Connecticut, USA

${ }^{10}$ The Russell H Morgan Department of Radiology and Radiological Science, Baltimore, Maryland, USA

${ }^{11}$ Department of Gastroenterology \& Hepatology, Amsterdam Gastroenterology \& Metabolism, Amsterdam, The Netherlands

${ }^{12}$ Gastroenterology, Endocrinology, Metabolism and Infectiology, University of Marburg, Marburg, Germany

${ }^{13}$ Gastroenterology and Hepatology, Amsterdam University Medical Centres, Amsterdam, The Netherlands
}

${ }^{14}$ Department of Pathology, Johns Hopkins University, Baltimore, Maryland, USA ${ }^{15}$ Division of Digestive and Liver Diseases, Columbia University Medical Center, New York City, New York, USA

${ }^{16}$ Division of Digestive and Liver Diseases, Columbia University, New York City, New York, USA

${ }^{17}$ Oncology, Johns Hopkins University, Baltimore, Maryland, USA

${ }^{18}$ Medicine, Johns Hopkins University, Baltimore, Maryland, USA

${ }^{19}$ Gastroenterology, Icahn School of Medicine at Mount Sinai, New York City, New York, USA

${ }^{20}$ New York University Medical Center, New York City, New York, USA

${ }^{21}$ University of Michigan, Ann Arbor, Michigan, USA

${ }^{22}$ Gastroenterology and Hepatology, Leiden University, Leiden, The Netherlands

Correction notice This article has been corrected since it published Online First. The author names and affiliations have been updated.

Collaborators International Cancer of the Pancreas Screening (CAPS) consortium Paolo Giorgio Arcidiacono, Reiko Ashida, Margreet Ausems, Marc Besselink,

Katharina Biermann, Bert Bonsing, Teri Brentnall, Amitabh Chak, Dayna Early, Carloz Fernandez-Del Castillo, Harold Frucht, Toru Furukawa, Steven Gallinger, Jennifer Geurts, Bas Groot Koerkamp, Pascal Hammel, Frederik Hes, Julio Iglesias-Garcia, Ihab Kamel, Masayuki Kitano, Günter Klöppel, Nanda Krak, Robert Kurtz, Richard Kwon, Jesse Lachter, Jeffrey Lee, Michael Levy, Giuseppe Malleo, Cheryl Meguid, Anirban Maitra, Daniel Margolis, Johan Offerhaus, Sara Olson, Salvatore Paiella, Walter Park, Gloria Petersen, Jan-Werner Poley, Francisco X Real, John Saltzman, Richard Schulick, Alina Stoita, Kyoichi Takaori, Masao Tanaka, Eric Tamm, Mark Topazian, Enrique Vazquez-Sequeiros, Frank Vleggaar, Wouter De Vos tot Nederveen Cappel, Charles Yeo, Martin Wasser, Anja Wagner, Michael Wallace, Christopher Wolfgang, Laura Wood.

Contributors The consensus meeting was initiated and organised by MG, MIC $\mathrm{MB}$, and $\mathrm{DLC}$. The consensus study design was developed by KAO and revised and approved by MB, DLC, MG, and MIC. Relevant literature was collected and summarised by KAO. Presentations during the development workgroup meeting were given by MG, RB, MDC, EF, TMG, SS, MIC, and MB, and the discussions facilitated by JF and JEvH. All authors except KAO, and all previously mentioned study collaborators provided the data (votes) for this study. Data were collected and analysed by KAO. The results were critically reviewed by MB, DLC, MG, and MIC. The manuscript was drafted by MG, KAO, DLC, MIC, and MB. All authors approved the final manuscript.

Funding The consensus meeting was supported by NIH grant U01CA210170 and by a donation of "Kom in beweging tegen alvleesklierkanker", "Living With Hope Foundation", and Hugh and Rachel Victor. MG is the Sol Goldman Professor of Pancreatic Cancer Research. AML is the Benjamin Baker Scholar.

Disclaimer JEvH received research funding from Abbott and Cook Medical; she is a consultant to Boston Scientific, Cook Medical, and Medtronics. DLC is a consultant to Tramedico. MB received research funding from Boston Scientific, Cook Medical, Pentax Medical, 3M; he is a consultant to Boston Scientific, Cook Medical, Pentax Medical, Mylan, MediRisk, and Medicom. PF is a consultant to Olympus, Cook Medical, Ethicon Endosurgery and received research funding from Boston Scientific. RB has received research funding from Immunovia and Freenome. MIC received research funding from Pentax C2 Cryoballoon and Endogastric Solutions. DS received research funding from Immunovia, Sanofi and Tempus; she is on the Scientific Advisory Board for Nybo Therapeutics, Interpace and Tyme.

Competing interests The authors disclose the following: JEvH received research funding from Abbott and Cook Medical; she is a consultant to Boston Scientific, Cook Medical, and Medtronics. DLC is a consultant to Tramedico. MB received research funding from Boston Scientific, Cook Medical, Pentax Medical, 3M; he is a consultant to Boston Scientific, Cook Medical, Pentax Medical, Mylan, MediRisk, and Medicom. PF is a consultant to Olympus, Cook Medical, Ethicon Endosurgery and received research funding from Boston Scientific. RB has received research funding from Immunovia and Freenome. MIC received research funding from Pentax C2 Cryoballoon and Endogastric Solutions. DS received research funding from Immunovia, Sanofi and Tempus; she is on the Scientific Advisory Board for Nybo Therapeutics, Interpace and Tyme.

Patient consent for publication Not required.

Provenance and peer review Not commissioned; externally peer reviewed. Data availability statement All data relevant to the study are included in the article.

\section{ORCID iDs}

Michael Goggins http://orcid.org/0000-0002-4286-2296

Kasper Alexander Overbeek http://orcid.org/0000-0003-1829-9963

Thomas M Gress http://orcid.org/0000-0002-9333-5461

Walter Park http://orcid.org/0000-0001-8187-4188 


\section{REFERENCES}

1 Canto MI, Hruban RH, Fishman EK, et al. Frequent detection of pancreatic lesions in asymptomatic high-risk individuals. Gastroenterology 2012;142:796-804.

2 Al-Sukhni W, Borgida A, Rothenmund $\mathrm{H}$, et al. Screening for pancreatic cancer in a high-risk cohort: an eight-year experience. J Gastrointest Surg 2012;16:771-83.

3 Canto Ml, Goggins M, Hruban RH, et al. Screening for early pancreatic neoplasia in high-risk individuals: a prospective controlled study. Clin Gastroenterol Hepatol 2006;4:766-81.

4 Langer $\mathrm{P}$, Kann $\mathrm{PH}$, Fendrich $\mathrm{V}$, et al. Five years of prospective screening of high-risk individuals from families with familial pancreatic cancer. Gut 2009;58:1410-8.

5 Ludwig E, Olson SH, Bayuga S, et al. Feasibility and yield of screening in relatives from familial pancreatic cancer families. Am J Gastroenterol 2011;106:946-54.

6 Poley JW, Kluijt I, Gouma DJ, et al. The yield of first-time endoscopic ultrasonography in screening individuals at a high risk of developing pancreatic cancer. Am J Gastroenterol 2009;104:2175-81.

7 Vasen $\mathrm{H}$, Ibrahim I, Ponce CG, et al. Benefit of surveillance for pancreatic cancer in high-risk individuals: outcome of long-term prospective follow-up studies from three European expert centers. J Clin Oncol 2016;34:2010-9.

8 Canto MI, Goggins M, Yeo CJ, et al. Screening for pancreatic neoplasia in high-risk individuals: an EUS-based approach. Clin Gastroenterol Hepatol 2004;2:606-21.

9 Schneider R, Slater EP, Sina M, et al. German national case collection for familial pancreatic cancer (FaPaCa): ten years experience. Fam Cancer 2011;10:323-30.

10 Canto MI, Almario JA, Schulick RD, et al. Risk of neoplastic progression in individuals at high risk for pancreatic cancer undergoing long-term surveillance. Gastroenterology 2018;155:740-51.

11 Vasen HFA, Wasser M, van Mil A, et al. Magnetic resonance imaging surveillance detects early-stage pancreatic cancer in carriers of a p16-Leiden mutation. Gastroenterology 2011;140:850-6.

12 Verna EC, Hwang C, Stevens PD, et al. Pancreatic cancer screening in a prospective cohort of high-risk patients: a comprehensive strategy of imaging and genetics. Clin Cancer Res 2010;16:5028-37.

13 Boulkedid R, Abdoul H, Loustau M, et al. Using and reporting the Delphi method for selecting healthcare quality indicators: a systematic review. PLoS One 2011;6:e20476.

14 Schünemann HJ, Best D, Vist G, et al. Letters, numbers, symbols and words: how to communicate grades of evidence and recommendations. CMAJ 2003;169:677-80.

15 Klein AP, Brune KA, Petersen GM, et al. Prospective risk of pancreatic cancer in familial pancreatic cancer kindreds. Cancer Res 2004;64:2634-8.

16 Jacobs EJ, Chanock SJ, Fuchs CS, et al. Family history of cancer and risk of pancreatic cancer: a pooled analysis from the pancreatic cancer cohort Consortium (PanScan). Int J Cancer 2010;127:1421-8.

17 Mukewar SS, Sharma A, Phillip N, et al. Risk of pancreatic cancer in patients with pancreatic cysts and family history of pancreatic cancer. Clin Gastroenterol Hepatol 2018.

18 Tanaka M, Fernández-del Castillo C, Adsay V, et al. International consensus guidelines 2012 for the management of IPMN and McN of the pancreas. Pancreatology 2012;12:183-97.

19 European Study Group on Cystic Tumours of the Pancreas. European evidence-based guidelines on pancreatic cystic neoplasms. Gut 2018;67:789-804

20 Siegel RL, Miller KD, Jemal A. Cancer statistics, 2019. CA Cancer J Clin 2019;69:7-34

21 Owens DK, Davidson KW, Krist AH, et al. Screening for pancreatic cancer: US preventive services task force reaffirmation recommendation statement. JAMA 2019:322:438-44.

22 Goggins M, Schutte M, Lu J, et al. Germline BRCA2 gene mutations in patients with apparently sporadic pancreatic carcinomas. Cancer Res 1996;56:5360-4.

23 Roberts NJ, Jiao Y, Yu J, et al. ATM mutations in patients with hereditary pancreatic cancer. Cancer Discov 2012;2:41-6.

24 Jones S, Hruban RH, Kamiyama M, et al. Exomic sequencing identifies PALB2 as a pancreatic cancer susceptibility gene. Science 2009;324:217.

25 Kastrinos Fet al. Risk of pancreatic cancer in families with Lynch syndrome. JAMA 2009;302:1790-5.

26 Roberts NJ, Norris AL, Petersen GM, et al. Whole genome sequencing defines the genetic heterogeneity of familial pancreatic cancer. Cancer Discov 2016;6:166-75.

27 Rosendahl J, Witt H, Szmola R, et al. Chymotrypsin C (CTRC) variants that diminish activity or secretion are associated with chronic pancreatitis. Nat Genet 2008;40:78-82.

28 Witt $\mathrm{H}$, Beer S, Rosendahl J, et al. Variants in CPA1 are strongly associated with early onset chronic pancreatitis. Nat Genet 2013:45:1216-20.

29 Lowenfels AB, Maisonneuve P, DiMagno EP, et al. Hereditary pancreatitis and the risk of pancreatic cancer. International hereditary pancreatitis study group. J Nat/ Cancer Inst 1997;89:442-6.

30 Whitcomb DC. Genetic risk factors for pancreatic disorders. Gastroenterology 2013;144:1292-302.

31 Tamura K, Yu J, Hata T, et al. Mutations in the pancreatic secretory enzymes CPA1 and CPB1 are associated with pancreatic cancer. Proc Natl Acad Sci U S A 2018;115:4767-72.
32 Chaffee KG, Oberg AL, McWilliams RR, et al. Prevalence of germ-line mutations in cancer genes among pancreatic cancer patients with a positive family history. Genet Med 2018;20.

33 Grant RC, Selander I, Connor AA, et al. Prevalence of germline mutations in cancer predisposition genes in patients with pancreatic cancer. Gastroenterology 2015;148:556-64.

34 Shindo K, Yu J, Suenaga M, et al. Deleterious germline mutations in patients with apparently sporadic pancreatic adenocarcinoma. J Clin Oncol 2017;35:3382-90.

35 Hu C, Hart SN, Polley EC, et al. Association between inherited germline mutations in cancer predisposition genes and risk of pancreatic cancer. JAMA 2018;319:2401-9.

36 Lowery MA, Wong W, Jordan EJ, et al. Prospective evaluation of germline alterations in patients with exocrine pancreatic neoplasms. J Natl Cancer Inst 2018;110:1067-74

37 Wood LD, Yurgelun MB, Goggins MG. Genetics of familial and sporadic pancreatic cancer. Gastroenterology 2019;156:2041-55.

38 Yurgelun MB, Chittenden AB, Morales-Oyarvide V, et al. Germline cancer susceptibility gene variants, somatic second hits, and survival outcomes in patients with resected pancreatic cancer. Genet Med 2019;21:213-23.

39 Bannon SA, Montiel MF, Goldstein JB, et al. High prevalence of hereditary cancer syndromes and outcomes in adults with early-onset pancreatic cancer. Cancer Prev Res (Phila) 2018;11:679-86.

40 Lucas AL, Frado LE, Hwang C, et al. BRCA1 and BRCA2 germline mutations are frequently demonstrated in both high-risk pancreatic cancer screening and pancreatic cancer cohorts. Cancer 2014;120:1960-7.

41 Abe T, Blackford AL, Tamura K, et al. Deleterious germline mutations are a risk factor for neoplastic progression among high-risk individuals undergoing pancreatic surveillance. J Clin Oncol. 2019;37:1070-80.

42 Konings ICAW, Harinck F, Poley J-W, et al. Prevalence and progression of pancreatic cystic precursor lesions differ between groups at high risk of developing pancreatic cancer. Pancreas 2017:46:28-34.

43 Stoffel EM, McKernin SE, Brand R, et al. Evaluating susceptibility to pancreatic cancer: ASCO provisional clinical opinion. J Clin Oncol 2019;37:153-64.

44 Vasen HF, Gruis NA, Frants RR, et al. Risk of developing pancreatic cancer in families with familial atypical multiple mole melanoma associated with a specific 19 deletion of p16 (p16-Leiden). Int J Cancer 2000;87:809-11.

45 Breast Cancer Linkage Consortium. Cancer risks in BRCA2 mutation carriers. J Natl Cancer Inst 1999:91:1310-6.

46 Risch HA, McLaughlin JR, Cole DEC, et al. Population BRCA1 and BRCA2 mutation frequencies and cancer penetrances: a kin-cohort study in Ontario, Canada. J Natl Cancer Inst 2006;98:1694-706.

47 Roch AM, Schneider J, Carr RA, et al. Are BRCA1 and BRCA2 gene mutation patients underscreened for pancreatic adenocarcinoma? J Surg Oncol 2019;119:777-83.

48 Ginsburg GS, Wu RR, Orlando LA. Family health history: underused for actionable risk assessment. The Lancet 2019;394:596-603.

49 Brune KA, Lau B, Palmisano $E$, et al. Importance of age of onset in pancreatic cance kindreds. J Nat/ Cancer Inst 2010;102:119-26.

50 Potjer TP, van der Stoep N, Houwing-Duistermaat JJ, et al. Pancreatic cancerassociated gene polymorphisms in a nation-wide cohort of p16-Leiden germline mutation carriers; a case-control study. BMC Res Notes 2015;8:264.

51 Brand RE, Greer JB, Zolotarevsky E, et al. Pancreatic cancer patients who smoke and drink are diagnosed at younger ages. Clin Gastroenterol Hepatol 2009;7:1007-12.

52 Anderson MA, Zolotarevsky E, Cooper KL, et al. Alcohol and tobacco lower the age of presentation in sporadic pancreatic cancer in a dose-dependent manner: a multicenter study. Am J Gastroenterol 2012;107:1730-9.

53 Klein AP, Lindström S, Mendelsohn JB, et al. An absolute risk model to identify individuals at elevated risk for pancreatic cancer in the general population. PLOS One 2013;8:e72311.

54 Zerboni G, Signoretti M, Crippa S, et al. Systematic review and meta-analysis: prevalence of incidentally detected pancreatic cystic lesions in asymptomatic individuals. Pancreatology 2019;19:2-9.

55 Harinck F, Konings ICAW, Kluijt I, et al. A multicentre comparative prospective blinded analysis of EUS and MRI for screening of pancreatic cancer in high-risk individuals. Gut 2016;65:1505-13.

56 Wani S, Han S, Simon V, et al. Setting minimum standards for training in EUS and $E R C P$ : results from a prospective multicenter study evaluating learning curves and competence among advanced endoscopy trainees. Gastrointest Endosc 2019;89:1160-8.

57 Khashab MA, Yong E, Lennon AM, et al. EUS is still superior to multidetecto computerized tomography for detection of pancreatic neuroendocrine tumors. Gastrointest Endosc 2011;73:691-6.

58 Topazian M, Enders F, Kimmey M, et al. Interobserver agreement for EUS findings in familial pancreatic-cancer kindreds. Gastrointest Endosc 2007:66:62-7.

59 Brune K, Abe T, Canto M, et al. Multifocal neoplastic precursor lesions associated with lobular atrophy of the pancreas in patients having a strong family history of pancreatic cancer. Am J Surg Pathol 2006;30:1067-76.

60 Thiruvengadam SS, Chuang J, Huang R, et al. Chronic pancreatitis changes in highrisk individuals for pancreatic ductal adenocarcinoma. Gastrointestinal endoscopy 2018. 
61 Kang H-J, Lee JM, Joo I, et al. Assessment of malignant potential in intraductal papillary mucinous neoplasms of the pancreas: comparison between multidetector CT and MR imaging with MR cholangiopancreatography. Radiology 2016;279:128-39.

62 Sah RP, Sharma A, Nagpal S, et al. Phases of metabolic and soft tissue changes in months preceding a diagnosis of pancreatic ductal adenocarcinoma. Gastroenterology 2019;156:1742-52.

63 Danai LV, Babic A, Rosenthal MH, et al. Altered exocrine function can drive adipose wasting in early pancreatic cancer. Nature 2018;558:600-4.

64 Lugo-Fagundo C, Vogelstein B, Yuille A, et al. Deep learning in radiology: now the real work begins. J Am Coll Radiol 2018;15:364-7.

65 Chu LC, Park S, Kawamoto S, et al. Utility of CT Radiomics features in differentiation of pancreatic ductal adenocarcinoma from normal pancreatic tissue. AJR Am J Roentgenol 2019;213:349-57.

66 Bartsch DK, Slater EP, Carrato A, et al. Refinement of screening for familial pancreatic cancer. Gut 2016;65:1314-21.

67 Pozzi-Mucelli RM, Rinta-Kiikka I, Wünsche K, et al. Pancreatic MRI for the surveillance of cystic neoplasms: comparison of a short with a comprehensive imaging protocol. Eur Radiol 2017;27:41-50.

68 Ashida R, Tanaka S, Yamanaka H, et al. The role of transabdominal ultrasound in the diagnosis of early stage pancreatic cancer: review and single-center experience. Diagnostics 2018;9.

69 O'Brien DP, Sandanayake NS, Jenkinson C, et al. Serum CA19-9 is significantly upregulated up to 2 years before diagnosis with pancreatic cancer: implications for early disease detection. Clin Cancer Res 2015;21:622-31.

70 Jenkinson C, Elliott VL, Evans A, et al. Decreased serum thrombospondin-1 levels in pancreatic cancer patients up to 24 months prior to clinical diagnosis: association with diabetes mellitus. Clin Cancer Res 2016:22:1734-43.

71 Nolen BM, Brand RE, Prosser D, et al. Prediagnostic serum biomarkers as early detection tools for pancreatic cancer in a large prospective cohort study. PLoS One 2014;9:e94928.

72 Siu AL, U S Preventive Services Task Force. Screening for abnormal blood glucose and type 2 diabetes mellitus: U.S. preventive services task force recommendation statement. Ann Intern Med 2015;163:861-8.

73 Chari S, Leibson C, Rabe K, et al. Probability of pancreatic cancer following diabetes: a population-based study. Gastroenterology 2005;129:504-11.

74 Chari ST, Leibson CL, Rabe KG, et al. Pancreatic cancer-associated diabetes mellitus: prevalence and temporal association with diagnosis of cancer. Gastroenterology 2008;134:95-101.

75 Setiawan VW, Stram DO, Porcel J, et al. Pancreatic cancer following incident diabetes in African Americans and Latinos: the multiethnic cohort. J Nat/ Cancer Inst 2019;111:27-33.

76 Sharma A, Kandlakunta H, Nagpal SJS, et al. Model to determine risk of pancreatic cancer in patients with new-onset diabetes. Gastroenterology 2018;155:730-9.

77 Boursi B, Finkelman B, Giantonio BJ, et al. A clinical prediction model to assess risk for pancreatic cancer among patients with new-onset diabetes. Gastroenterology 2017; 152:840-850.e3.

78 Cohen JD, Javed AA, Thoburn C, et al. Combined circulating tumor DNA and protein biomarker-based liquid biopsy for the earlier detection of pancreatic cancers. Proc Natl Acad Sci U S A 2017:114:10202-7.

79 Cohen JD, Li L, Wang Y, et al. Detection and localization of surgically resectable cancers with a multi-analyte blood test. Science 2018;359:926-30.

80 Cristiano S, Leal A, Phallen J, et al. Genome-wide cell-free DNA fragmentation in patients with cancer. Nature 2019;570:385-9.

81 Groot VP, Riel SL, Javed AA, et al. Detection of recurrent pancreatic cancer with circulating tumor DNA in a clinical laboratory improvement amendments (CLIA) laboratory setting. Clin Cancer Res 2019;25:4973-84

82 Mellby LD, Nyberg AP, Johansen JS, et al. Serum biomarker signature-based liquid biopsy for diagnosis of early-stage pancreatic cancer. J Clin Oncol 2018:36:2887-94.

83 Kim J, Bamlet WR, Oberg AL, et al. Detection of early pancreatic ductal adenocarcinoma with thrombospondin-2 and CA19-9 blood markers. Sci Trans/ Med 2017;9:eaah5583.

84 Yang KS, Im H, Hong S, et al. Multiparametric plasma eV profiling facilitates diagnosis of pancreatic malignancy. Sci Trans/ Med 2017;9:eaal3226.

85 Pea A, Yu J, Marchionni L, et al. Genetic analysis of small well-differentiated pancreatic neuroendocrine tumors identifies subgroups with differing risks of liver metastases. Ann Surg 2018:1.

86 Partelli S, Mazza M, Andreasi V, et al. Management of small asymptomatic nonfunctioning pancreatic neuroendocrine tumors: limitations to apply guidelines into real life. Surgery 2019;166:157-63.

87 Sallinen VJ, Le Large TYS, Tieftrunk E, et al. Prognosis of sporadic resected small ( $\leq 2$ $\mathrm{cm})$ nonfunctional pancreatic neuroendocrine tumors - a multi-institutional study. HPB 2018:20:251-9.

88 Falconi M, Eriksson B, Kaltsas G, et al. ENETS consensus guidelines update for the management of patients with functional pancreatic neuroendocrine tumors and non-functional pancreatic neuroendocrine tumors. Neuroendocrinology 2016:103:153-71.
89 Yu J, Blackford AL, dal Molin M, et al. Time to progression of pancreatic ductal adenocarcinoma from low-to-high tumour stages. Gut 2015;64:1783-9.

90 Franke FS, Matthäi E, Slater EP, et al. German National Case Collection for familial pancreatic Cancer ( $\mathrm{FaPaCa}$ ) - acceptance and psychological aspects of a pancreatic cancer screening program. Hered Cancer Clin Pract 2018;16:17.

91 Falconi M, Crippa S, Chari S, et al. Quality assessment of the guidelines on cystic neoplasms of the pancreas. Pancreatology 2015;15:463-9.

92 Crippa S, Bassi C, Salvia R, et al. Low progression of intraductal papillary mucinous neoplasms with worrisome features and high-risk stigmata undergoing nonoperative management: a mid-term follow-up analysis. Gut 2017;66:495-506.

93 Wu W, Dodson R, Makary MA, et al. A contemporary evaluation of the cause of death and long-term quality of life after total pancreatectomy. World I Surg 2016:40:2513-8

94 Zakaria HM, Stauffer JA, Raimondo M, et al. Total pancreatectomy: short- and longterm outcomes at a high-volume pancreas center. World J Gastrointest Surg 2016;8:634-42

95 Canto MI, Almario JA, Schulick RD, et al. Risk of neoplastic progression in high-risk individuals undergoing long-term surveillance for pancreatic cancer. Gastroenterology 2018.

96 Canto MI, Kerdsirichairat T, Yeo CJ, et al. Surgical outcomes after pancreatic resection of screening-detected lesions in individuals at high risk for developing pancreatic cancer. J Gastrointest Surg. In Press 2019;29.

97 Tamura K, Ohtsuka T, Ideno N, et al. Treatment strategy for main duct intraductal papillary mucinous neoplasms of the pancreas based on the assessment of recurrence in the remnant pancreas after resection. Ann Surg 2014;259:360-8.

98 Pea A, Yu J, Rezaee N, et al. Targeted DNA sequencing reveals patterns of local progression in the pancreatic remnant following resection of intraductal papillary mucinous neoplasm (IPMN) of the pancreas. Ann Surg 2017;266:133-41.

99 Makohon-Moore AP, Matsukuma K, Zhang M, et al. Precancerous neoplastic cells can move through the pancreatic ductal system. Nature 2018;561:201-5.

100 Luchini C, Pea A, Yu J, et al. Pancreatic cancer arising in the remnant pancreas is not always a relapse of the preceding primary. Mod Pathol 2019;32:659-65.

101 Ibrahim I, Sibinga Mulder BG, Bonsing B, et al. Risk of multiple pancreatic cancers in CDKN2A-p16-Leiden mutation carriers. Eur J Hum Genet 2018;26:1227-9.

102 Basturk O, Hong S-M, Wood LD, et al. A revised classification system and recommendations from the Baltimore consensus meeting for neoplastic precursor lesions in the pancreas. Am J Surg Pathol 2015;39:1730-41.

103 Shi C, Klein AP, Goggins M, et al. Increased prevalence of precursor lesions in familia pancreatic cancer patients. Clin Cancer Res 2009;15:7737-43.

104 Yu J, Sadakari Y, Shindo K, et al. Digital next-generation sequencing identifies lowabundance mutations in pancreatic juice samples collected from the duodenum of patients with pancreatic cancer and intraductal papillary mucinous neoplasms. Gut 2017:66:1677-87.

105 Felsenstein M, Noë M, Masica DL, et al. Ipmns with co-occurring invasive cancers: neighbours but not always relatives. Gut 2018:67:1652-62

106 Suenaga M, Yu J, Shindo K, et al. Pancreatic juice mutation concentrations can help predict the grade of dysplasia in patients undergoing pancreatic surveillance. Clin Cancer Res 2018;24:2963-74.

107 Hruban RH, Gaida MM, Thompson E, et al. Why is pancreatic cancer so deadly? the pathologist's view. J Pathol 2019;248:131-41.

108 Klein AP, Wolpin BM, Risch HA, et al. Genome-wide meta-analysis identifies five new susceptibility loci for pancreatic cancer. Nat Commun 2018;9:556.

109 Mayers JR, Wu C, Clish CB, et al. Elevation of circulating branched-chain amino acids is an early event in human pancreatic adenocarcinoma development. Nat Med 2014;20:1193-8.

110 Corral JE, Das A, Bruno MJ, et al. Cost-effectiveness of pancreatic cancer surveillance in high-risk individuals. Pancreas 2019;48:526-36.

111 Hruban RH. Is the early detection of pancreatic cancer possible? it is good news, bad news. Pancreas 2019:48:591-3.

112 Owens DK, Davidson KW, Krist AH, et al. Screening for pancreatic cancer: US Preventive Services Task Force Reaffirmation Recommendation Statement methods and rationale for the early detection of pancreatic cancer. Highlights from the "2010 ASCO Gastrointestinal Cancers Symposium". Orlando, FL, USA. January 22-24, 2010. JAMA 2019;322:438-44

113 USPSTF. Pancreatic cancer: screening, 2019. Available: https://www.uspreventiveserv icestaskforce.org/Page/Document/UpdateSummaryFinal/pancreatic-cancer-screening [Accessed 13 Apr 19].

114 Gray JAM, Patnick J, Blanks RG. Maximising benefit and minimising harm of screening. BMJ 2008:336:480-3.

115 Welch HG. Screening mammography--a long run for a short slide? N Engl J Med 2010;363:1276-8.

116 Welch HG, Gorski DH, Albertsen PC. Trends in metastatic breast and prostate cancer — lessons in cancer dynamics. N Engl J Med 2015;373:1685-7.

117 Konings I, Canto Ml, Almario JA, et al. Detection and outcome of pancreatic cancer surveillance in high-risk individuals: results from the caps Consortium. BJS open 2019;3:656-65. 


\section{Correction: Management of patients with increased risk for familial pancreatic cancer: updated recommendations for the international cancer of the pancreas screening (CAPS) Consortium}

Goggins M, Overbeek KA, Brand R et al. Management of patients with increased risk for familial pancreatic cancer: updated recommendations for the International Cancer of the Pancreas Screening (CAPS) Consortium. Gut 2020;68:7-17.

The affiliation for 2 and 23 should be the same and should be

Gastroenterology and Hepatology, Erasmus University Medical Center, Rotterdam, The

Netherlands

They are cited differently as below.

Gastroenterology and Hepatology, Erasmus Medical Centre, Rotterdam, The Netherlands

Gastoenterology and Hepatology, Erasmus University Rotterdam, Rotterdam, The Netherlands

Also the affiliation of the Johns Hopkins University authors should also include The Sol Goldman Pancreatic Cancer Research Centre.

Figure one has been added for clarity:

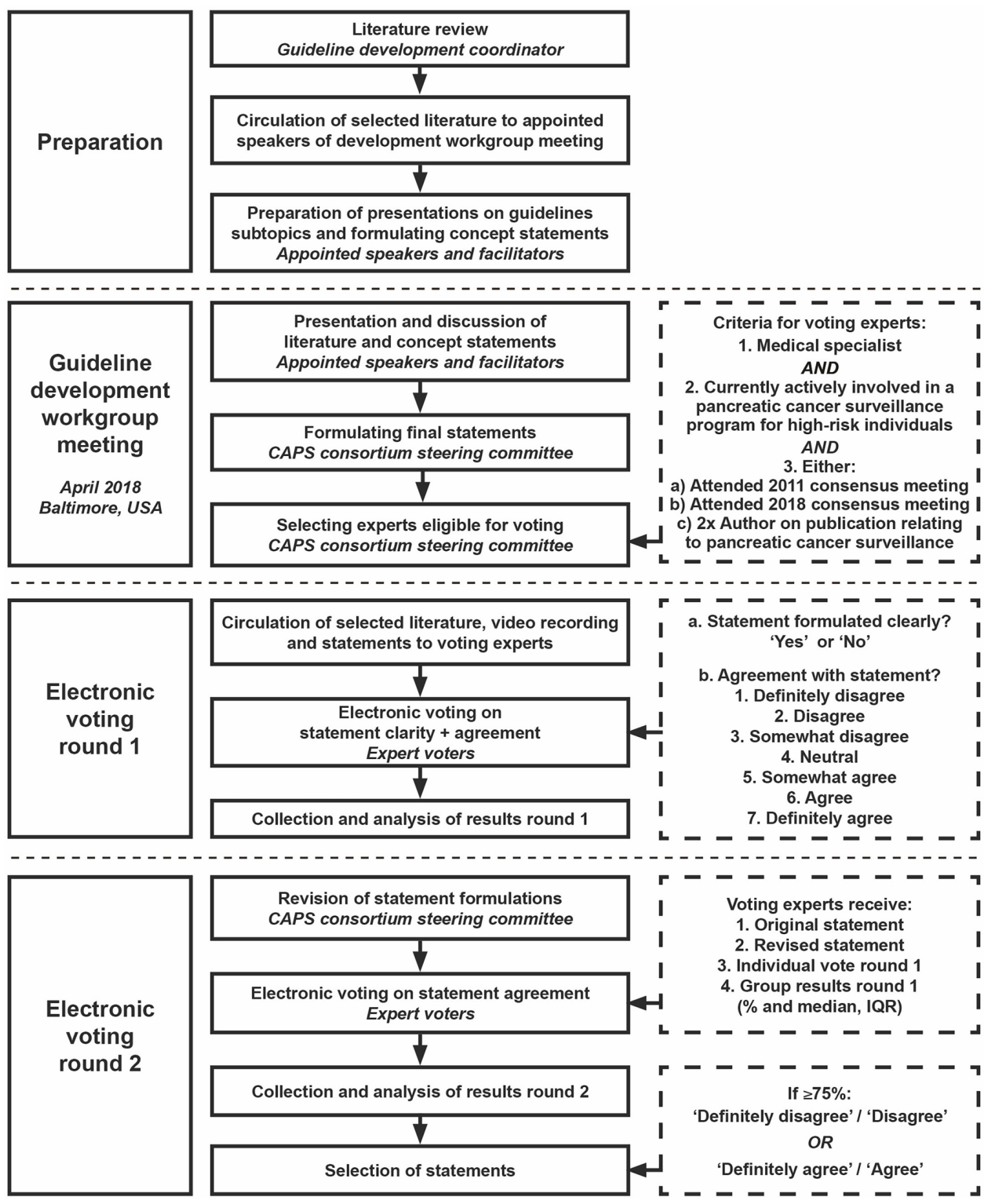

Figure 1 
(c) Author(s) (or their employer(s)) 2020. No commercial re-use. See rights and permissions. Published by BMJ.

Gut 2020;69:e3. doi:10.1136/gutjnl-2019-319352corr1

(D) Check for updates 